\title{
Manipulation of Polyhydroxybutyrate Properties through Blending with Ethyl-Cellulose for a Composite Biomaterial
}

\author{
Rodman T. H. Chan, ${ }^{1}$ Christopher J. Garvey, ${ }^{2}$ Helder Marçal, ${ }^{1}$ Robert A. Russell, ${ }^{1,2}$ \\ Peter J. Holden, ${ }^{2}$ and L. John R. Foster ${ }^{1}$ \\ ${ }^{1}$ Bio/Polymer Research Group, Centre for Advanced Macromolecular Design, School of Biotechnology and Biomolecular Science, \\ University of New South Wales, Sydney, NSW 2052, Australia \\ ${ }^{2}$ Australian Nuclear Science and Technology Organisation, Lucas Heights, NSW 2234, Australia
}

Correspondence should be addressed to L. John R. Foster, j.foster@unsw.edu.au

Received 6 May 2011; Accepted 30 May 2011

Academic Editor: Shanfeng Wang

Copyright (C) 2011 Rodman T. H. Chan et al. This is an open access article distributed under the Creative Commons Attribution License, which permits unrestricted use, distribution, and reproduction in any medium, provided the original work is properly cited.

Polyhydroxybutyrate (PHB) is widely used as a biomaterial in medical and tissue-engineering applications, a relatively high crystallinity limits its application. Blending PHB with ethyl-cellulose (EtC) was readily achieved to reduce PHB crystallinity and promote its degradation under physiological conditions without undue influence on biocompatibility. Material strength of composite films remained unchanged at $6.5 \pm 0.6 \mathrm{MPa}$ with $40 \%(\mathrm{w} / \mathrm{w})$ EtC loadings. Phase separation between the two biopolymers was determined with PHB crystallinity decreasing from $63 \%$ to $47 \%$ for films with the same loading. This reduction in crystallinity supported an increase in the degradation rates of composite films from 0.39 to $0.81 \% \mathrm{wk}^{-1}$ for $\mathrm{PHB}$ and its composite, respectively. No significant change in morphology and proliferation of olfactory ensheathing cells were observed with the composites despite significant increases in average surface roughness $\left(R_{a}\right)$ of the films from 2.90 to $3.65 \mu \mathrm{m}$ for PHB and blends with $80 \%(\mathrm{w} / \mathrm{w})$ EtC, respectively.

\section{Introduction}

Polyhydroxyalkanoates (PHAs) are a family of biopolyesters synthesised by a range of microbial species under conditions of environmental stress with excess of carbon [1]. Currently, PHAs consisting of one or more of over 150 different monomer unit have been identified and include the commercially produced polyhydroxybutyrate (PHB) $[2,3]$. $\mathrm{PHB}$ is the most commonly studied member of the PHA family is biodegradable and biocompatible and used as both a bioplastic and biomaterial for medical devices (Figure 1) [4].

Microbial PHB is comprised of $\beta$-hydroxybutyric acid (HBA) monomer units, which is also one of the ketone bodies produced by mammalian cells under conditions of starvation and diabetes and is thought to facilitate biocompatibility in its microbial counterpart which, in the absence of endotoxins, does not trigger any cytotoxic response in mammals [5]. Foster and Tighe have shown that microbial
HBA is chemically identical to the mammalian HBA and is recognised by mammalian enzymes $[5,6]$. Microbially produced PHB does not trigger an immune and inflammatory response or cause anastomotic failures [7]. As a biomaterial, PHB has been used for various biomedical devices such as sutures, prosthetic devices, and drug delivery systems and for surgical applications [8]. However, the crystalline nature of PHB, its brittleness and low flexibility, long degradation rate under physiological conditions, and poor processability limit its potential for tissue engineering [9]. Modification of $\mathrm{PHB}$ physiochemical and material properties through copolymerising and blending have demonstrated successful manipulation of these properties particularly as a bioplastic for environmental applications but with limited success in biomedical scenarios $[10,11]$.

Similar to PHB, ethyl-cellulose (EtC) is also an FDA(Food and Drug Administration, USA) approved biomaterial and is widely used as a blood coagulant, coatings for pharmaceutical tablets, and matrices for poorly soluble drugs 


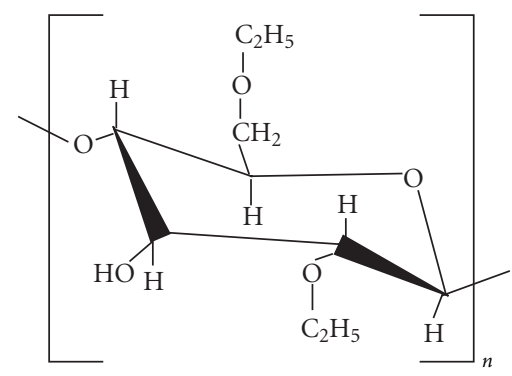

(a)

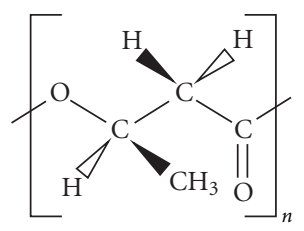

(b)
FIGURE 1: Chemical formulae for biomacromolecules (a) EthylCellulose (EtC) and (b) Poly(3-hydroxybutyrate), (PHB).

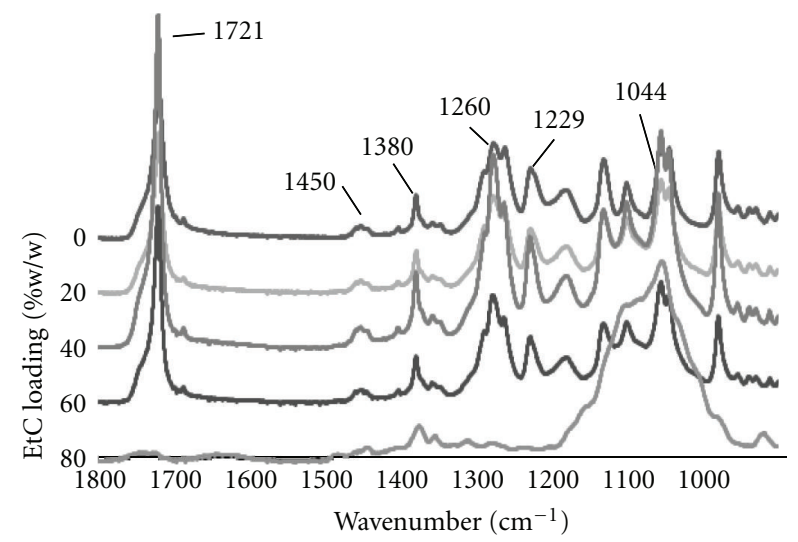

FIGURE 2: FTIR spectra for PHB-EtC composite films with varying loads of EtC (\%w/w).

[12]. Ethyl-cellulose has also been used as a framework in drug-delivery systems for stabilising drug release through the cellulose hydrophilic surface interface [13]. Furthermore, studies have shown that EtC is susceptible to enzyme digestion in human body [14]. In contrast, degradation of $\mathrm{PHB}$ proceeds through abiotic hydrolysis and under physiological conditions is a slow process taking years to completely degrade [15]. The rate of PHB degradation has been enhanced by blending PHB with other polymers such as cellulose triacetate (CTAc) and PEG $[16,17]$.

While there are a variety of reports on PHB-based blends, studies using cellulose derivatives are limited. In the study here, we report on the manipulation of $\mathrm{PHB}$ physiochemical and material properties through the addition of ethyl-cellulose as a blending agent with the production of composite PHB-Etc biomaterial films (Figure 1).

\section{Experimental}

2.1. Reagents. Polyhydroxybutyrate (PHB) of natural origin, ethyl cellulose (48\% ethoxyl) and Trypsin were purchased from Sigma Aldrich (Sydney, Australia; Figure 1). Analytical grade chloroform and dimethyl sulfoxide (DMSO) were purchased from Univar, (Seven Hills, Australia). Mammalian cell growth medium, fetal bovine serum (FBS) and Penicillin/Streptococcus antibiotic were obtained from GibcoInvitrogen (Sydney, Australia). OECs were routinely cultured

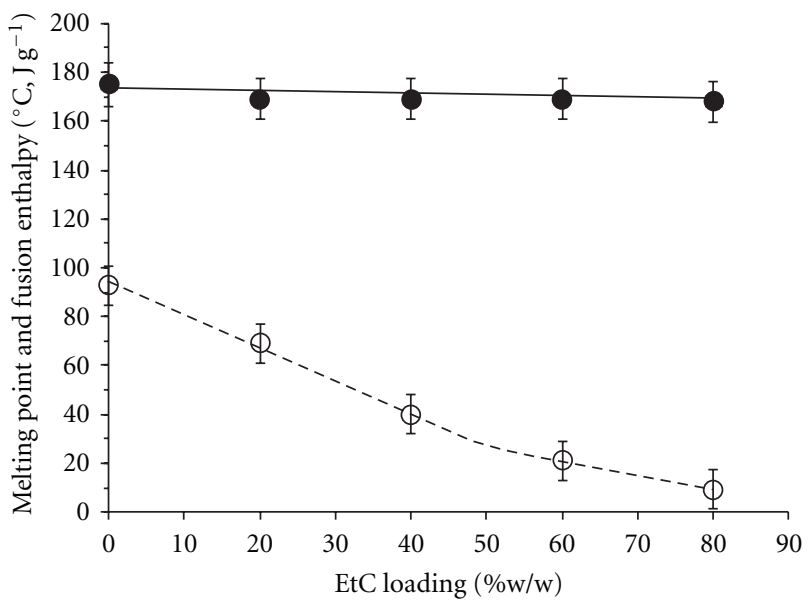

FIGURE 3: Change in thermal properties for PHB-EtC composite films with variations in EtC loading $(\% \mathrm{w} / \mathrm{w})$; (O) melting point $\left({ }^{\circ} \mathrm{C}\right)$ and $(\bigcirc)$ fusion enthalpy $\left(\mathrm{J} \mathrm{g}^{-1}\right)$.

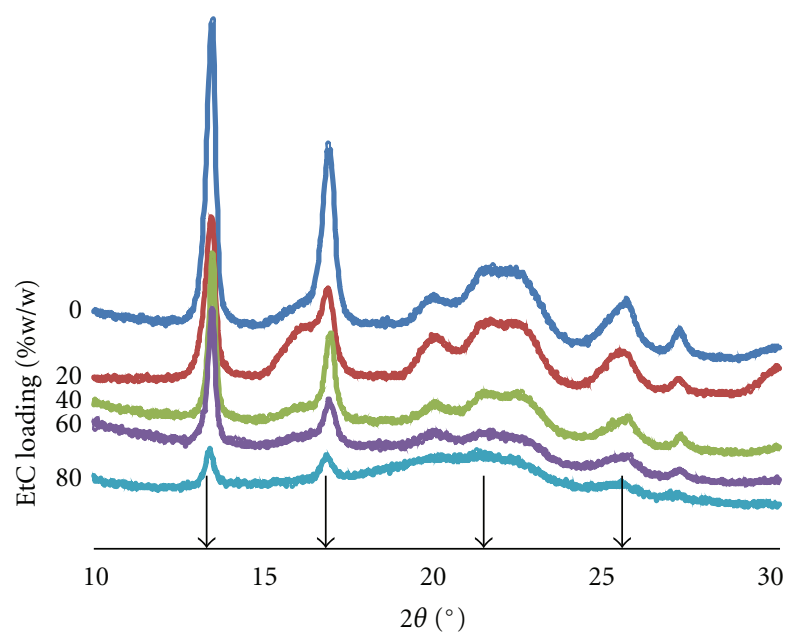

FIGURE 4: X-ray diffractograms of PHB-EtC composite films with variations in EtC loading (\%w/w).

in Dulbecco's Modified Eagle's Medium (DMEM/F12) supplemented with 10\% FBS purchased from Lonza (USA).

2.2. Film Fabrication. Biopolymer films were produced by solvent casting as per Zhang et al. [18]. PHB and EtC samples with weight ratios of $100: 0,80: 20,60: 40,40: 60$, and $20: 80$ $(\mathrm{w} / \mathrm{w})$ were dissolved in heated chloroform in a sterile sealed vessel $\left(5 \% \mathrm{w} / \mathrm{v}, 160 \mathrm{rpm}, 50^{\circ} \mathrm{C}\right)$. The solution was allowed to $\operatorname{cool}\left(22^{\circ} \mathrm{C}, 160 \mathrm{rpm}, 15 \mathrm{mins}\right)$ before pouring into sterile, glass Petri dishes and the solvent evaporated by standing (12 hours, $22^{\circ} \mathrm{C}$ ). The resulting films were subsequently maintained at $40^{\circ} \mathrm{C}$ under vacuum for 48 hours to remove any solvent residues before annealing at $70^{\circ} \mathrm{C}$ for 10 days.

2.3. Material characterisation. Material properties of $\mathrm{PHB}$ and PHB-EtC films were analysed using a tensile testing instrument (Instron-5543, USA) at $22^{\circ} \mathrm{C}$ with $30 \%$ relative humidity. Films samples $(30 \mathrm{~mm} \times 15 \mathrm{~mm})$ were clamped 


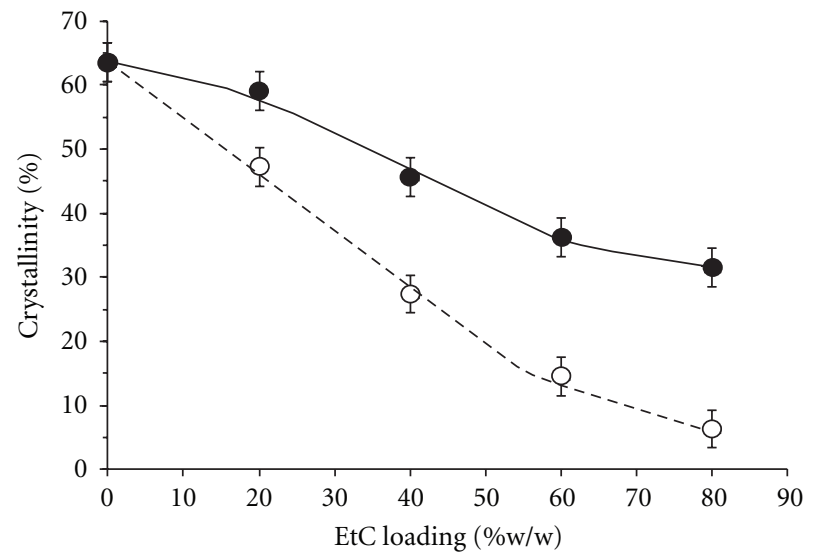

(a)

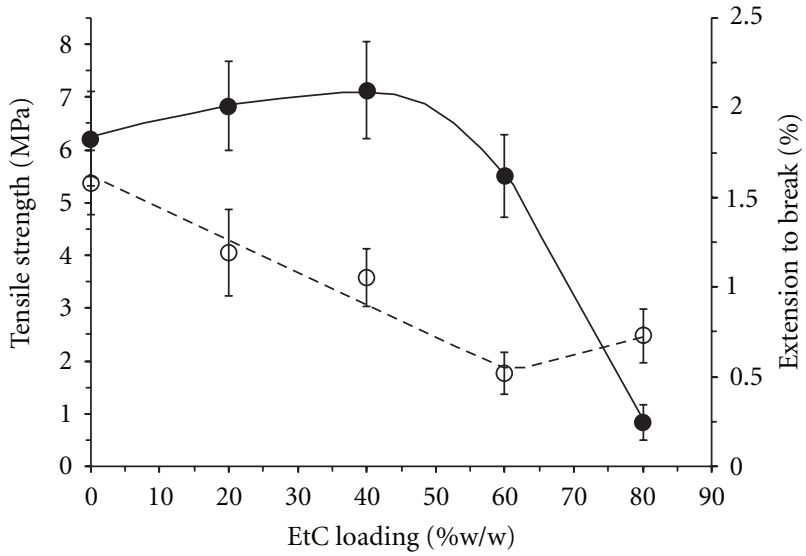

(b)

FIGURE 5: Change in (a) crystallinity: break $(\bigcirc, \%)$ for PHB-EtC composite films with variation in EtC loading (\%, w/w).

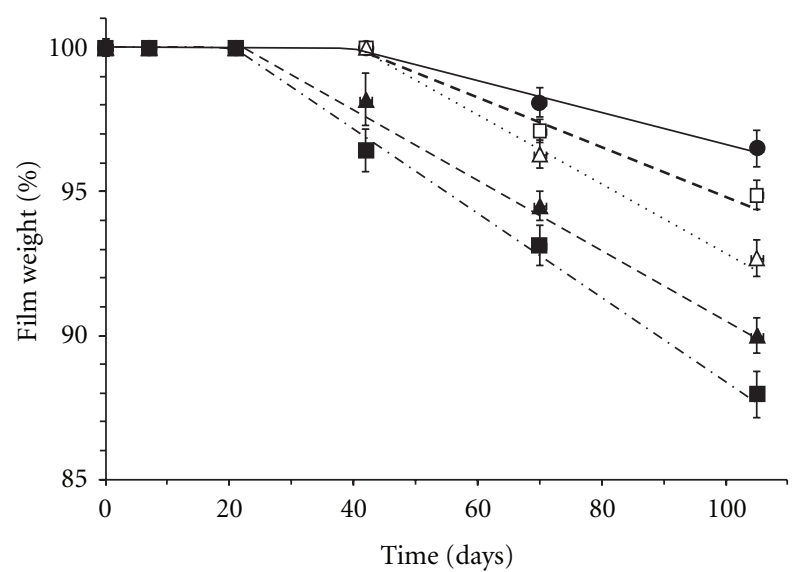

Figure 6: Change in degradation of PHB-EtC composite films with variations in EtC loading ( 0 ; $\square 20 ; \Delta 40 ; \boldsymbol{\Delta} 60, \square 80 \%$, w/w) under physiological conditions $\left(37^{\circ} \mathrm{C}, \mathrm{pH} 7.4,140 \mathrm{rpm}\right)$.

to the calibrated tensiometer using pneumatic grips which slowly moved apart $\left(20 \mathrm{~mm} \mathrm{~min}^{-1}\right)$. The maximum load, tensile strength and extension at break were calculated using Bluehill computer software (USA). Means from at least 10 samples were determined $(n=10)$.

Thermal properties of the PHB-EtC films were examined using a DSC-1 Star ${ }^{\mathrm{e}}$ system (Mettler Toledo, USA). Samples

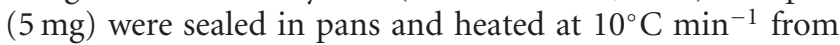
$25^{\circ} \mathrm{C}$ to $200^{\circ} \mathrm{C}$ to obtain the melting temperature $\left(T_{m}\right)$ and enthalpy of fusion $\left(\Delta H_{f}\right)$. Samples were then cooled at the same rate from $200^{\circ} \mathrm{C}$ to $-50^{\circ} \mathrm{C}$ and reheated from $-50^{\circ} \mathrm{C}$ to $25^{\circ} \mathrm{C}$ to obtain glass transition temperatures $\left(T_{g}\right)$. The blend $\left(\right.$ Blend- $\left.\mathrm{X}_{\mathrm{c}}\right)$ and $\mathrm{PHB}\left(\mathrm{PHB}-\mathrm{X}_{\mathrm{c}}\right)$ phase crystallinity were calculated using (1), respectively [19]

$$
\begin{gathered}
\text { Blend- } X_{c}=\frac{\Delta H f}{\Delta H_{f}^{\circ}} \times 100, \\
\text { PHB- } X_{c}=X_{c} \frac{\text { blend }}{W_{\mathrm{PHB}}} \times 100 \%,
\end{gathered}
$$

where $\Delta H_{f}^{\circ}$ is the enthalpy of fusion for PHB $\left(146 \mathrm{Jg}^{-1}\right)$ [19] and $W_{\mathrm{PHB}}$ is the percentage of PHB in the blended film. Means of at least 15 samples were determined $(n=15)$.

$\mathrm{X}$-ray diffraction patterns of the PHB-EtC composites were acquired using a Philips X'pert Material Research Diffraction (MRD) System (Holland). Film samples $(20 \times$ $20 \mathrm{~mm}$ ) were secured on glass slides and aligned with $2 \theta$, $z$-axis and omega scans (scattering angle range of $2 \theta=10$ $30^{\circ}$ and scan step size of $0.02^{\circ}$ continuous). Radiation of wavelength $1.5406 \AA$ (Cu K-Alpha) were generated using a power of $45 \mathrm{kV}$ and tube current of $40 \mathrm{~mA}$.

Fourier transform infra-red (FTIR) were made on the PHB-EtC films using a Nicolet iS10 FTIR spectrometer (Thermo scientific, USA). FTIR spectra were acquired between 900 and $1800 \mathrm{~cm}^{-1}$ wave numbers by accumulating 64 scans at a resolution of $0.5 \mathrm{~cm}^{-1}$. Optics were purged with nitrogen to suppress signals from carbon dioxide and water vapour.

2.4. Degradation Studies. Preweighed samples of PHBEtC films $(25 \times 10 \mathrm{~mm})$ were sterilised through gammairradiation and placed into $2 \mathrm{ml}$ Eppendorf tubes. Samples were incubated $\left(37^{\circ} \mathrm{C}, 150 \mathrm{rpm}\right)$ following the addition of phosphate buffered saline $(0.1 \mathrm{M}, \mathrm{pH} 7.4)$ with penicillin (100 units $\left.\mathrm{mL}^{-1}\right)$, streptomycin $\left(100 \mu \mathrm{g} \mathrm{mL}^{-1}\right)$ and fungizone-amphotericin B $\left(2.5 \mu \mathrm{g} \mathrm{mL}^{-1}\right)$. At periodic intervals samples were removed, filtered, and dried in a dessicator $\left(40^{\circ} \mathrm{C}, 24 \mathrm{~h}\right)$ before allowing to acclimatise at $22^{\circ} \mathrm{C}$ (atmospherically equilibrated weight). Means of four samples per time point, per sample, were determined. The degradation experiment, modified from Foster et al., was carried out over 105 days [6]. Weight loss (\%) was calculated as:

$$
W(\%)=\frac{W_{t}}{W_{0}} \times 100 \%,
$$

where $W$ is the percentage weight loss and $W_{0}$ and $W_{t}$ are the initial weight and weight after incubation, respectively; means of 5 samples were determined $(n=5)$. 


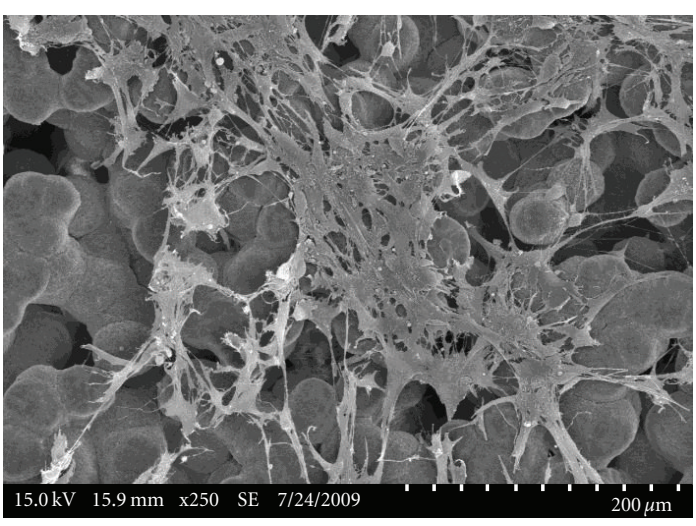

(a)

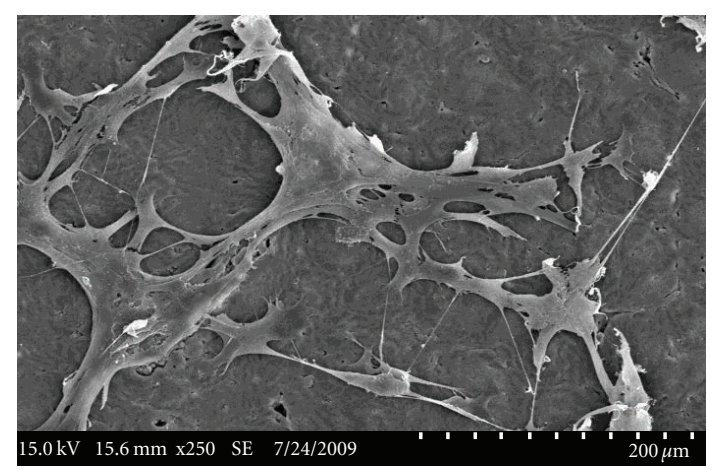

(c)

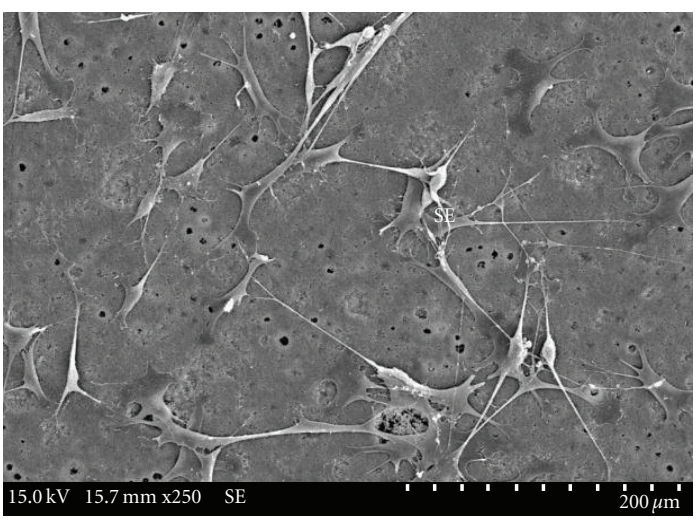

(e)

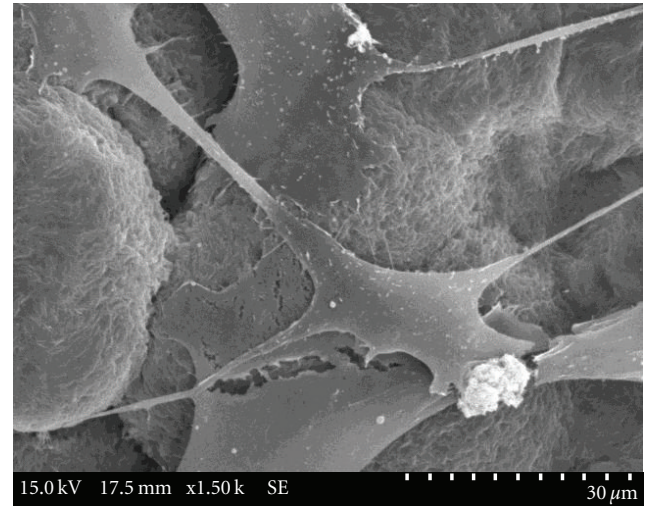

(b)

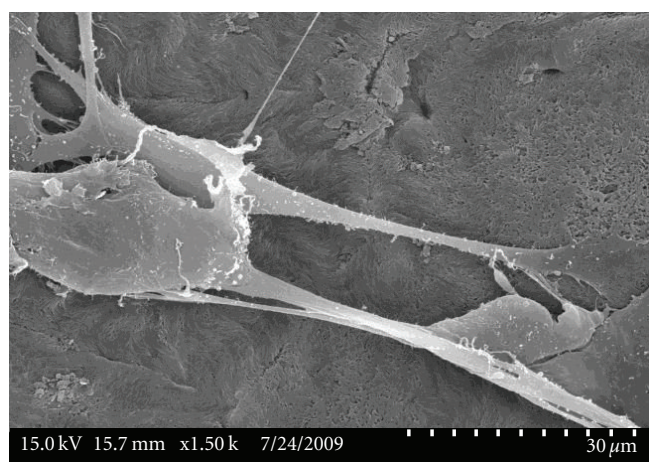

(d)

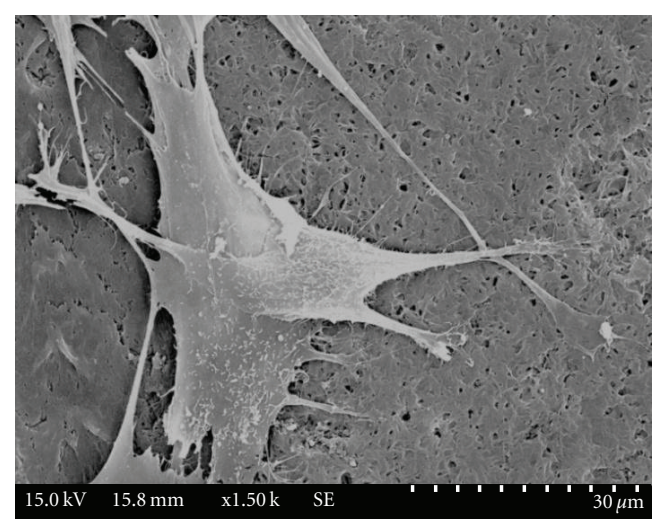

(f)

FIGURE 7: SEMs illustrating attachment of olfactory ensheathing cells (OECs) on PHB-EtC composite films with variations in EtC loadings after 24 hours cultivation (a, d) PHB films with $0 \%$ (b, e) $20 \%$ and (c, f) $40 \%(w / w)$ ETC loadings; $(\mathrm{a}-\mathrm{c}) \times 250 \mathrm{magn}, \mathrm{bar}=200 \mu \mathrm{m},(\mathrm{d}-\mathrm{f})$ $\times 1500$ magn, bar $=30 \mu \mathrm{m}$.

2.5. Cell Studies. Murine olfactory ensheathing cells (OECs) were cultivated in medium containing (DMEM, 10\% FBS, 250 unit penicillin, $250 \mu \mathrm{g} \mathrm{mL}^{-1}$ streptomycin and $1 \mu \mathrm{g} \mathrm{mL}^{-1}$ fungizone-amphotericin $\mathrm{B}$ ) in T-75 tissue culture flasks incubated at $37^{\circ} \mathrm{C}$ with $5 \% \mathrm{CO}_{2}$ [20] . OECs were removed from the flask using trypsin $(2.5 \%)$ at $70 \%$ confluence and cell populations of approximately $2 \times 10^{5}$ cells $\mathrm{mL}^{-1}$ used to inoculate films samples $(13 \times 13 \mathrm{~mm})$. At periodic intervals, samples were sacrificed, and the films were rinsed twice with $10 \mathrm{~mL}$ of PBS, $2 \mathrm{~mL}$ of trypsin $(2.5 \%)$ was subsequently added before incubation $\left(37^{\circ} \mathrm{C}, 2 \mathrm{mins}\right)$. Cell proliferation was observed over 3 days and cell viability was calculated using a haemocytometer and the trypan blue exclusion technique [20]. Samples were conducted in triplicate $(n=3)$.

2.6. Microscopy. Cell attachment to PHB-based films were visualised using microscopy. Films were rinsed twice with phosphate buffer saline (PBS, 1\%) and fixed in 2.5\% glutaraldehyde in $0.1 \mathrm{M}$ PBS buffer ( $\mathrm{pH} 7.2,4^{\circ} \mathrm{C}, 12$ hours). Films were then washed with PBS buffer three times for 5 minutes duration and postfixed in $1 \%$ osmium tetroxides $\left(\mathrm{OsO}_{4}, 1\right.$ hour $)$. After a buffer wash, samples were sequentially dehydrated in ethanol $(30 \%, 50 \%, 70 \%, 80 \%$, $90 \%, 95 \%$, and $100 \%, 10$ minutes each) and critical point 


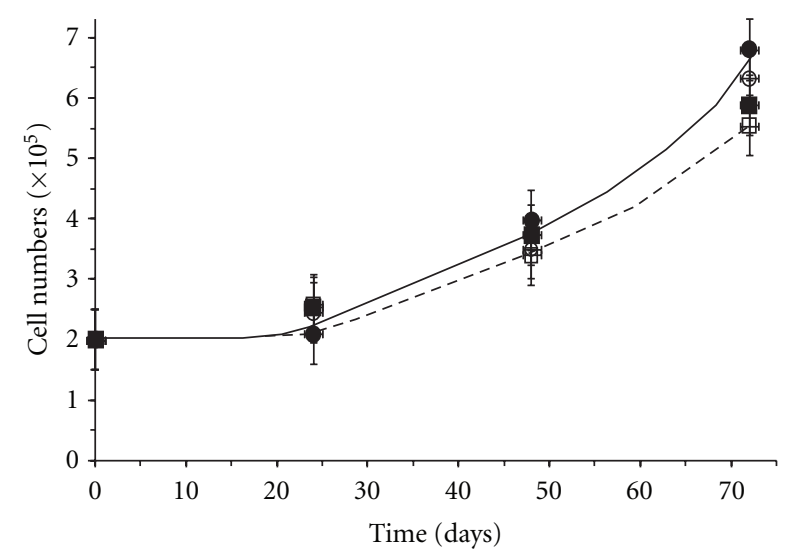

Figure 8: Change in proliferation of OECs as number of cells attached to PHB-EtC films with time for variations in EtC loadings

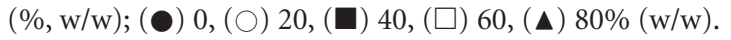

dried, adapted from Chung et al. [21]. Specimens were mounted on aluminium stubs and surfaces were coated with a layer of gold particles using a sputter coater (Emitech K550x, England). Samples were subsequently examined using scanning electron microscopy (Hitachi S3400-I, Japan) at $15 \mathrm{kV}$ and $750 \mathrm{~mA}$.

The microtopographies of the PHB-EtC films were mapped using the reflection mode of a confocal scanning laser microscope (CSLM, Leica model TCS-SP, Germany) at excitation and emission wavelengths of 458 and $440-470 \mathrm{~nm}$, respectively. Multiple images through the $z$-plane were recorded ( step size $=2.5 \mu \mathrm{m}$ ). A total of 30 images were used to generate a $3 \mathrm{D}$ depth map and calculate average surface roughness values $\left(R_{a}\right)$ according to ISO 4298 (2000) using ImageJ software (National Institute of Health, USA):

$$
R_{a}=\frac{1}{L} \int_{0}^{L}|z| d x
$$

where the average surface roughness $\left(R_{a}\right)$ was calculated from the sampling length $(L)$, the plane $(z)$ and the variations of irregularities $(d x)$ from the mean line [3].

2.7. Statistical Analysis. The data are displayed as a mean value with standard deviation of each group. A Student's $t$ test was performed to test significance with $95 \%$ confidence.

\section{Results and Discussion}

3.1. PHB-Etc Film Characterisation. FTIR is sensitive to local molecular environments and as a consequence has been widely applied to investigate interactions between macromolecules during crystallisation [22]. In the study here, FTIR measurements on the solvent cast PHB films showed a characteristic spectrum with peaks at 1721 and $1229 \mathrm{~cm}^{-1}$ assigned to stretching of the $\mathrm{C}=\mathrm{O}$ groups and $\mathrm{C}-\mathrm{O}-\mathrm{C}$ bonds, respectively, in the crystalline matrix. While peaks at 1450 and $1380 \mathrm{~cm}^{-1}$ were characteristic of asymmetric and symmetric methyl group deformation, those at 1260,1229 and $1044 \mathrm{~cm}^{-1}$ were assigned to C-O-C stretching with $\mathrm{C}-\mathrm{H}$ deformation, $\mathrm{C}-\mathrm{O}-\mathrm{C}$ stretching in the amorphous regions and $\mathrm{C}-\mathrm{CH}_{3}$ stretching $[23,24]$. Blending $\mathrm{PHB}$ with increasing loads of EtC gradually reduced the peak intensities in the spectra belonging to crystalline $\mathrm{PHB}$ as the amorphous content of the composites increased. Contrary to Kumagai et al. who reported blends of PHB with cellulose triacetate [16], we did not resolve spectral shifts in peaks suggesting no specific interactions between the two biopolymer components (i.e., hydrogen bonding). The spectra appeared to be simple linear combinations of semicrystalline PHB and EtC (Figure 2).

Differential scanning calorimetry (DSC) showed no significant change in the melting point $\left(\mathrm{mp}, 175 \pm 4^{\circ} \mathrm{C}\right)$ and glass transition temperature $\left(\mathrm{Tg}, 1 \pm 1^{\circ} \mathrm{C}\right.$ ) of $\mathrm{PHB}$ in the composite (Figure 3). However, PHB fusion enthalpies $\left(\Delta H_{f}\right)$ decreased from 92 to $10 \mathrm{Jg}^{-1}$ in films with $80 \%$ $(\mathrm{w} / \mathrm{w})$ EtC loading. X-ray diffraction patterns and maxima, observed at 14, 17, 22 and $26^{\circ}$, of the PHB-Etc composites were consistent with previous studies (Figure 4) [25]. As the EtC loading increased the relative peak intensities were reduced, such that the composite with $80 \%$ (w/w) EtC loading showed a much broader spectrum with the peaks at 14 and $17^{\circ}$ only just noticeable. No disruption of the PHB crystal structure was observed, further supporting FTIR data suggesting the apparent separation of crystalline PHB from amorphous $\mathrm{PHB}$ and $\mathrm{EtC}$ regions into semicrystalline matrices with EtC chains trapped in the PHB lamellae [26, 27]. The results reported here are consistent with that of Scandola who investigated phase behaviour in PHB and Etc blends and the influence this blending had on environmental degradation of these composites [27].

Differentiation between the crystalline and amorphous regions revealed that as the EtC content in the blend increased, the percentage crystallinity of the films decreased from $63.5 \pm 3.3 \%$ [19] in PHB films to $9.2 \pm 1.5 \%$ when the films possessed only 20\% (w/w) PHB. (Figure 5(a)). Similarly, the increasing load of EtC disrupted the crystalline process for the PHB which decreased by approximately $32 \%$ to $31.5 \pm 4.2 \%$ with $80 \%(\mathrm{w} / \mathrm{w})$ EtC loading consistent with the work of Zhang et al. who reported blends of PHB with starch acetate (Figure 5(a)) [18].

Changes in film crystallinity as a consequence of blending with EtC, anticipates an influence on the material properties of the PHB-EtC composite films. However, Figure 5(b) shows no significant change in tensile strength as the EtC loading increased to $40 \%(\mathrm{w} / \mathrm{w})$ before a dramatic decrease from approximately $6.83 \pm 1.05$ to $0.84 \pm 0.33 \mathrm{MPa}$ (Figure 5(b)). In contrast, extension to break of the films showed an apparently linear decrease from $1.58+0.38 \%$ for PHB to $0.52+0.12 \%$ for composites containing $60 \%(\mathrm{w} / \mathrm{w})$ EtC $(P<0.05)$. Garvey et al. have shown that crystallisation increases in annealed PHB-EtC films when compared to similarly annealed PHB films [28]. Furthermore, The use of relatively high temperatures during film fabrication has been shown to support nucleation and spherulite formation in $\mathrm{PHB}$ films while reducing the distance between the $\mathrm{PHB}$ granules in the matrix [9]. In the study here, $\mathrm{PHB}-$ EtC composites with $20 \%$ (w/w) EtC loadings annealed at $25^{\circ} \mathrm{C}$ exhibited optimal mechanical properties, since tensile 


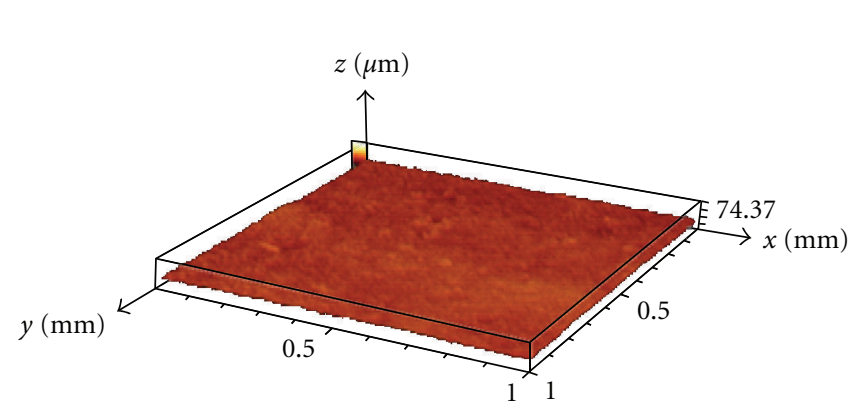

(a)

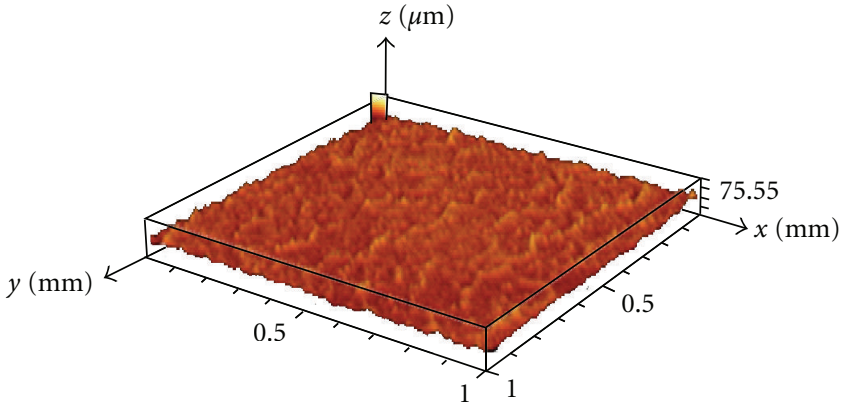

(b)

Figure 9: Surface microtopographies of (a) PHB and (b) PHB-EtC composite with $80 \% \mathrm{EtC}$ (w/w) films.

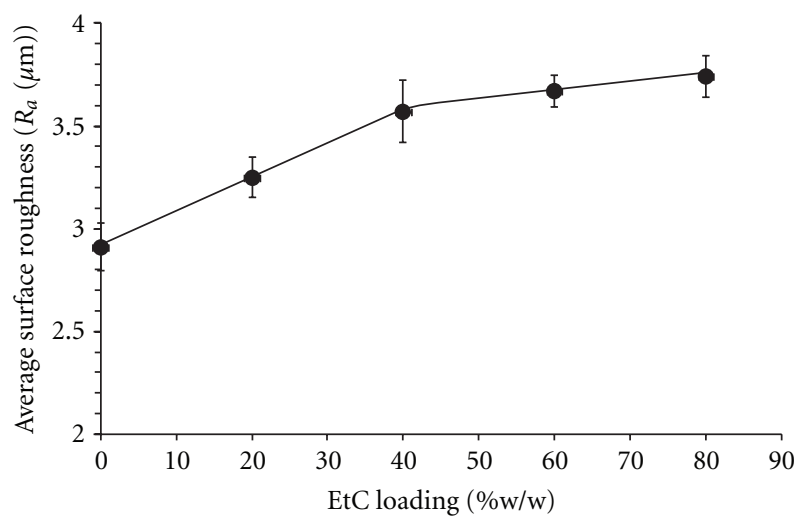

FIGURE 10: Change in average surface roughness $\left(R_{a}, \mu \mathrm{m}\right)$ of PHBEtC composite films with variations in EtC loading $(\%, w / w)$.

strength and extension at break point were maintained (Figure 5(b)).

3.2. Film Degradation. In addition to influencing material properties, crystallinity can also dictate abiotic degradation behaviour. Reduction of PHB fractional crystallinity makes films more permeable to water molecules and consequently increase hydrolysis of the ester bonds [29]. When incubated under physiological conditions ( $\left.\mathrm{pH} 7.4,37^{\circ} \mathrm{C}, 160 \mathrm{rpm}\right) \mathrm{PHB}$ and composites films with loadings up to $40 \%$ (w/w) EtC no significant weight loss for the first 40 days, while films with higher EtC loadings exhibited weight loss earlier after only 20 days (Figure 6). Figure 6 clearly shows that increasing the EtC loading in the PHB-EtC films increased their degradation, such that PHB films had lost approximately 3.5\% of their initial weight after 105 days incubation while composites with $20 \%$ (w/w) PHB lost about $12 \%$ of their initial weight. Furthermore, weight loss rates were linear and increased significantly $(P>0.005)$ from $0.39 \% \mathrm{wk}^{-1}$ for PHB films to 0.81 and $1.34 \% \mathrm{wk}^{-1}$ for PHB blended with 40 and $80 \%$ $(\mathrm{w} / \mathrm{w}) \mathrm{EtC}$, respectively.

3.3. Cellular Responses to PHB-Etc Films. Blends of PHB with EtC are commercially attractive as both biopolymers are FDA approved and have demonstrated success as biomedical devices. Blending with EtC reduces the PHB crystallinity and permits manipulation of film material properties and more favourable degradation under physiological conditions. In the study here, the influence of EtC on biocompatibility on the PHB films was compared using adult olfactory ensheathing cells (OECs). Figure 7 shows that OECs readily attached to $\mathrm{PHB}$ and its composite with 20\% (w/w) EtC and exhibited healthy morphology with many filament extensions comparable to cells in an asynchronous control with the absence of biomaterials. Furthermore, while cell proliferations appeared to be slightly greater for the $\mathrm{PHB}$ homopolymer, these were not significant in the course of this study (Figure 8). In all cases, OEC viability was maintained over $95 \%$ for each of the films during duration of the study.

Irregular porous surfaces of PHB-based films have been shown to influence cell adhesion and growth [29]. Microtopographies of the films clearly show changes in surface structures as a consequence of EtC blending (Figure 9). Depth maps derived from these images were used to determine the average surface roughness's $\left(R_{a}\right)$ as per ISO 4298 (Figure 10). PHB films exhibited a $R_{a} 2.91 \pm 0.12 \mu \mathrm{m}$, as the EtC content increased the $R_{a}$ also increased. Composite films with $80 \%(\mathrm{w} / \mathrm{w})$ EtC loadings had the most irregular surface with a significantly greater $R_{a}$ value of $3.74 \pm 0.10 \mu \mathrm{m}$ (Figure 10, $P>0.001$ ). In comparison to the study here, Zhao et al. have reported that increasing surface roughness in PHA films reduced murine fibroblast attachment, with cells apparently preferring a smoother surface [30].

\section{Conclusions}

The highly crystalline nature of PHB limits its applications as a biomaterial for medical devices. Manipulation of composition and processing are used to promote more favourable properties in PHB-based devices $[31,32]$. In the research reported here, we have combined $\mathrm{PHB}$ with another FDA-approved biomaterial, ethyl cellulose. Blending of these two components produced composite films with significant reductions in crystallinity which promoted their degradation under physiological conditions but did not significantly compromise their material properties or biocompatibility. It is anticipated that with the added control of annealing we can effectively "tailor" PHB-based biomaterials through 
blending to support biomedical device fabrication such as nerve conduits for neuronal regeneration as well as the development of tissue engineering matrices.

\section{References}

[1] F. M. Kapritchkoff, A. P. Viotti, R. C. P. Alli et al., "Enzymatic recovery and purification of polyhydroxybutyrate produced by Ralstonia eutropha," Journal of Biotechnology, vol. 122, no. 4, pp. 453-462, 2006.

[2] T. Freier, "Biopolyesters in tissue engineering applications," Advances in Polymer Science, vol. 203, no. 1, pp. 1-61, 2006.

[3] C. A. Woolnough, T. Charlton, L. H. Yee, M. Sarris, and L. J. R. Foster, "Surface changes in polyhydroxyalkanoate films during biodegradation and biofouling," Polymer International, vol. 57, no. 9, pp. 1042-1051, 2008.

[4] L. J. Chen and M. Wang, "Production and evaluation of biodegradable composites based on PHB-PHV copolymer," Biomaterials, vol. 23, no. 13, pp. 2631-2639, 2002.

[5] L. J. R. Foster and B. J. Tighe, "Enzymatic assay of hydroxybutyric acid monomer formation in poly $(\beta$-hydroxybutyrate) degradation studies," Biomaterials, vol. 16, no. 4, pp. 341-343, 1995.

[6] L. J. R. Foster and B. J. Tighe, "In vitro hydrolytic degradation of centrifugally spun polyhydroxybutyrate-pectin composite fibres," Polymer International, vol. 58, no. 12, pp. 1442-1451, 2009.

[7] S. Philip, T. Keshavarz, and I. Roy, "Polyhydroxyalkanoates: biodegradable polymers with a range of applications," Journal of Chemical Technology and Biotechnology, vol. 82, no. 3, pp. 233-247, 2007.

[8] Z. W. Dai, X. H. Zou, and G. Q. Chen, "Poly(3hydroxybutyrate-co-3-hydroxyhexanoate) as an injectable implant system for prevention of post-surgical tissue adhesion," Biomaterials, vol. 30, no. 17, pp. 3075-3083, 2009.

[9] J. W. You, H. J. Chiu, and T. M. Don, "Spherulitic morphology and crystallization kinetics of melt-miscible blends of poly(3hydroxybutyrate) with low molecular weight poly(ethylene oxide)," Polymer, vol. 44, no. 15, pp. 4355-4362, 2003.

[10] K. Zhao, Y. Deng, J. C. Chen, and G. Q. Chen, "Polyhydroxyalkanoate (PHA) scaffolds with good mechanical properties and biocompatibility," Biomaterials, vol. 24, no. 6, pp. 10411045, 2003.

[11] C. Chen, C. H. Yu, Y. C. Cheng, P. H. F. Yu, and M. K. Cheung, "Biodegradable nanoparticles of amphiphilic triblock copolymers based on poly(3-hydroxybutyrate) and poly(ethylene glycol) as drug carriers," Biomaterials, vol. 27, no. 27, pp. 4804-4814, 2006.

[12] M. M. Crowley, B. Schroeder, A. Fredersdorf et al., "Physicochemical properties and mechanism of drug release from ethyl cellulose matrix tablets prepared by direct compression and hot-melt extrusion," International Journal of Pharmaceutics, vol. 269, no. 2, pp. 509-522, 2004.

[13] H. Dong, Q. Xu, Y. Li, S. Mo, S. Cai, and L. Liu, "The synthesis of biodegradable graft copolymer cellulose-graftpoly(l-lactide) and the study of its controlled drug release," Colloids and Surfaces B: Biointerfaces, vol. 66, no. 1, pp. 26-33, 2008.

[14] J. Chen, S. Jo, and K. Park, "Polysaccharide hydrogels for protein drug delivery," Carbohydrate Polymers, vol. 28, no. 1, pp. 69-76, 1995.

[15] D. S. Rosa, N. T. Lotto, D. R. Lopes, and C. G. F. Guedes, "The use of roughness for evaluating the biodegradation of poly- $\beta$-(hydroxybutyrate) and poly- $\beta$-(hydroxybutyrateco- $\beta$-valerate)," Polymer Testing, vol. 23, no. 1, pp. 3-8, 2004.

[16] Y. Kumagai, Y. Kanesawa, and Y. Doi, "Enzymatic degradation of microbial poly(3-hydroxybutyrate) films," Makromolekular Chemie, vol. 193, no. 1, pp. 53-57, 1992.

[17] X. J. Loh, K. K. Tan, X. Li, and J. Li, "The in vitro hydrolysis of poly(ester urethane)s consisting of poly[(R)3-hydroxybutyrate] and poly(ethylene glycol)," Biomaterials, vol. 27, no. 9, pp. 1841-1850, 2006.

[18] L. Zhang, X. Deng, and Z. Huang, "Miscibility, thermal behaviour and morphological structure of poly(3hydroxybutyrate) and ethyl cellulose binary blends," Polymer, vol. 38, no. 21, pp. 5379-5387, 1997.

[19] P. J. Barham, A. Keller, E. L. Otun, and P. A. Holmes, "Crystallization and morphology of a bacterial thermoplastic: poly-3-hydroxybutyrate," Journal of Materials Science, vol. 19, no. 9, pp. 2781-2794, 1984.

[20] H. Marçal, N. S. Wanandy, V. Sanguanchaipaiwong et al., "BioPEGylation of polyhydroxyalkanoates: influence on properties and satellite-stem cell cycle," Biomacromolecules, vol. 9, no. 10, pp. 2719-2726, 2008.

[21] R. S. Chung, A. Woodhouse, S. Fung et al., "Olfactory ensheathing cells promote neurite sprouting of injured axons in vitro by direct cellular contact and secretion of soluble factors," Cellular and Molecular Life Sciences, vol. 61, no. 10, pp. 1238-1245, 2004.

[22] C. Vogel, E. Wessel, and H. W. Siesler, "FT-IR imaging spectroscopy of phase separation in blends of poly(3hydroxybutyrate) with poly(L-lactic acid) and $\operatorname{poly}(\varepsilon-$ caprolactone)," Biomacromolecules, vol. 9, no. 2, pp. 523-527, 2008.

[23] T. Furukawa, H. Sato, R. Murakami et al., "Structure, dispersibility, and crystallinity of poly(hydroxybutyrate)/ poly(Llactic acid) blends studied by FT-IR microspectroscopy and differential scanning calorimetry," Macromolecules, vol. 38, no. 15, pp. 6445-6454, 2005.

[24] L. J. R. Foster, V. Sanguanchaipaiwong, C. L. Gabelish, J. Hook, and M. Stenzel, "A natural-synthetic hybrid copolymer of polyhydroxyoctanoate-diethylene glycol: biosynthesis and properties," Polymer, vol. 46, no. 17, pp. 6587-6594, 2005.

[25] B. L. Hurrell and R. E. Cameron, "A wide-angle X-ray scattering study of the ageing of poly(hydroxybutyrate)," Journal of Materials Science, vol. 33, no. 7, pp. 1709-1713, 1998.

[26] T. Wang, G. Cheng, S. Ma, Z. Cai, and L. Zhang, "Crystallization behavior, mechanical properties, and environmental biodegradability of $\operatorname{poly}(\beta$-hydroxybutyrate)/cellulose acetate butyrate blends," Journal of Applied Polymer Science, vol. 89, no. 8, pp. 2116-2122, 2003.

[27] M. Scandola, "Polymer blends based on bacterial poly(3hydroxybutyrate)," Canadian Journal of Microbiology, vol. 41, supplement 1, pp. 310-315, 1995.

[28] C. J. Garvey, R. A. Russell, V. M. Garamus, F. Boue, L. J. R. Foster, and P. J. Holden, Small Angle Neutron Scattering Study of the Interface between Ethylcellulose and Polyhydroxyalkanoate Blends during Annealing, Abstract, SAS2009, ANSTO, Oxford, UK, 2009.

[29] I. I. Muhamad, L. K. Joon, and M. Noor, "Comparing the degradation of poly- $\beta$-(hydroxybutyrate), 39-46 poly- $\beta$ (hydroxybutyrate-co- $\beta$-valerate)(PHBV) and PHBV/cellulose triacetate blend," Malaysian Polymer Journal, vol. 1, no. 1, pp. 39-46, 2006. 
[30] Z. Kai, D. Ying, and C. Guo-Qiang, "Effects of surface morphology on the biocompatibility of polyhydroxyalkanoates," Biochemical Engineering Journal, vol. 16, no. 2, pp. 115-123, 2003.

[31] L. J. R. Foster, "Biosynthesis, properties and potential of natural-synthetic hybrids of polyhydroxyalkanoates and polyethylene glycols," Applied Microbiology and Biotechnology, vol. 75, no. 6, pp. 1241-1247, 2007.

[32] B. Hazer, "Amphiphilic poly(3-hydroxyalkanoate)s: potential candidates for medical applications," Energy and Power Engineering, vol. 2, no. 1, pp. 31-38, 2010. 

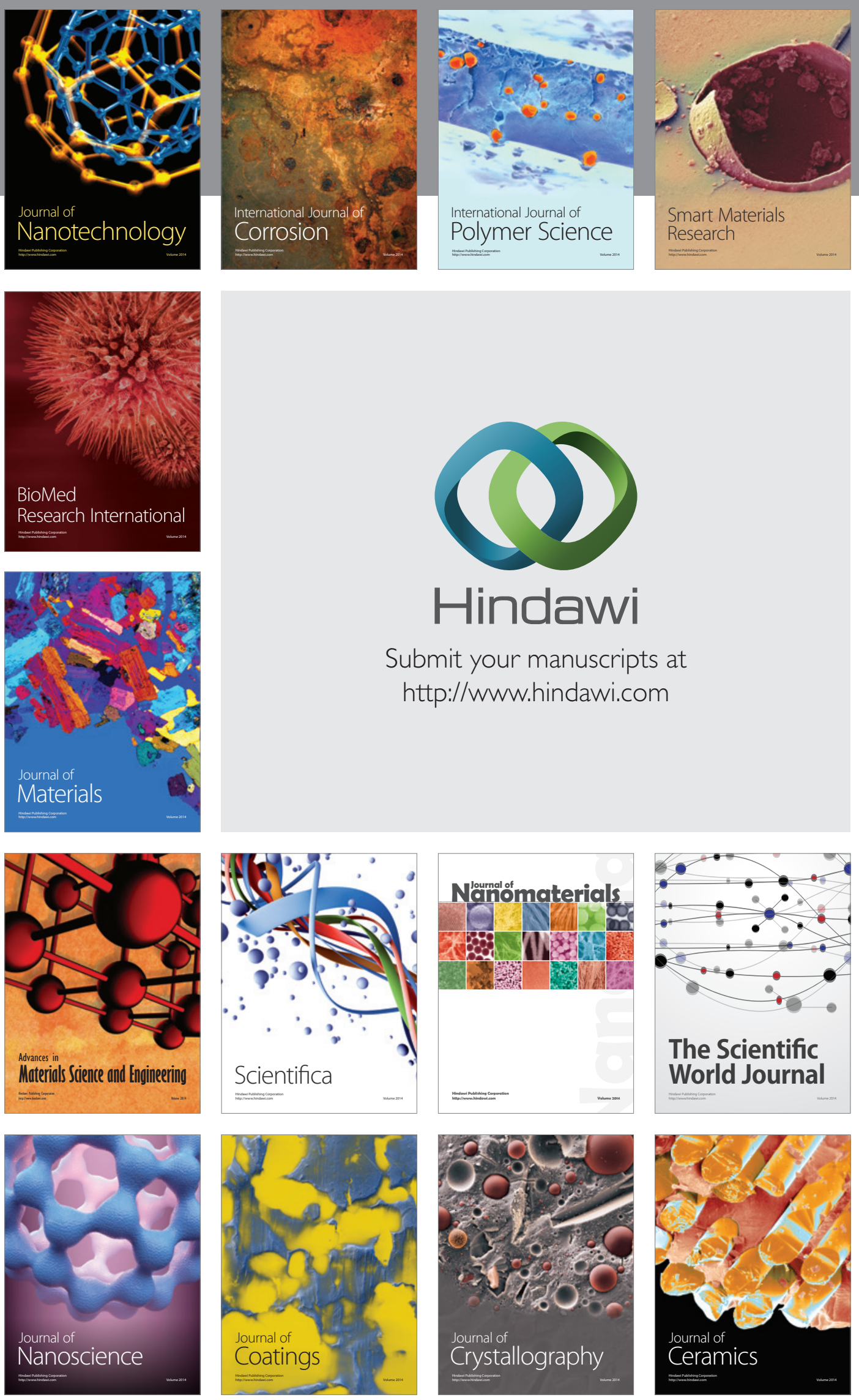

The Scientific World Journal

Submit your manuscripts at

http://www.hindawi.com

\section{World Journal}

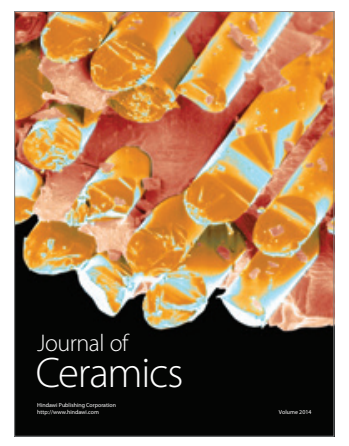

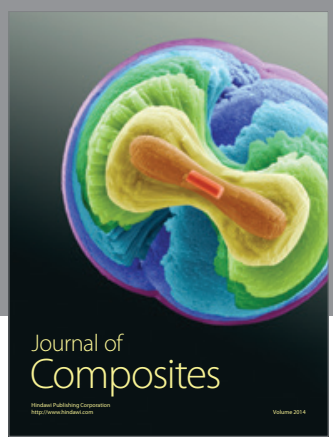
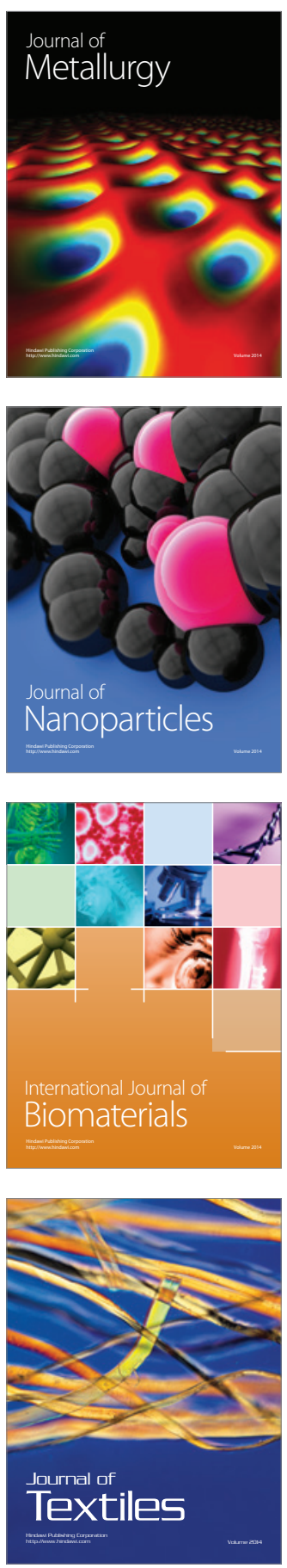